\title{
Seasonal dependence of energetic electron precipitation: Evidence for a global role of lightning
}

\author{
E. S. Gemelos, ${ }^{1}$ U. S. Inan, ${ }^{1,2}$ M. Walt, ${ }^{1}$ M. Parrot ${ }^{3}$ and J. A. Sauvaud ${ }^{4}$ \\ Received 7 August 2009; revised 12 October 2009; accepted 15 October 2009; published 12 November 2009.
}

[1] Analysis of the DEMETER spacecraft particle data shows that energetic electron precipitation exhibits a seasonal dependence consistent with lighting-induced electron precipitation (LEP). Over the United States, energetic electron fluxes in the slot region (between $L=2$ and 3) are significantly higher in the northern summer than in the winter, consistent with the seasonal variation of lightning activity in the Northern Hemisphere. The association of precipitating fluxes with lightning is explored using lightning location data from the National Lightning Detection Network (NLDN) and VLF wave data on DEMETER. The increased precipitation of particles into the drift loss cone over the Northern Hemisphere in summer is consistent with expected pitch-angle scattering by lightning-generated whistler waves, indicating that lightning is a significant contributor to the loss of slot region electrons. Citation: Gemelos, E. S., U. S. Inan, M. Walt, M. Parrot, and J. A. Sauvaud (2009), Seasonal dependence of energetic electron precipitation: Evidence for a global role of lightning, Geophys. Res. Lett., 36, L21107, doi:10.1029/ 2009GL040396.

\section{Introduction}

[2] Transient bursts of lightning-induced electron precipitation (LEP) are observed directly on satellites [Voss et al., 1984, 1998; Inan et al., 2007] and via scattering of very low frequency (VLF) signals from ionization enhancements they produce in the D-region ionosphere [Inan et al., 1988]. Such electrons are in the so-called bounce loss cone, i.e., destined to precipitate within $<1$ s. Energetic electrons scattered by whistlers at longitudes west of the spacecraft but destined to precipitate at the South Atlantic Anomaly (SAA) in the course of their eastward drift are in the socalled drift loss cone, and enhanced fluxes of such electrons have also been observed in association with lightning [Blake et al., 2001].

[3] In LEP events, individual lightning discharges launch whistler-mode wave packets that undergo cyclotron-resonant interaction with trapped electrons. These interactions cause pitch-angle scattering of electrons, sometimes by as much as

\footnotetext{
${ }^{1}$ Space, Telecommunications, and Radioscience Laboratory, Stanford University, Stanford, California, USA.

${ }^{2}$ Also at Electrical Engineering Department, KOC University, Sariyer, Turkey.

${ }^{3}$ Laboratoire de Physique et Chimie de l'Environnement et de l'Espace, Centre National de la Recherche Scientifique, Orléans, France.

${ }^{4}$ Centre d'Etude Spatiale des Rayonnements, Centre National de la Recherche Scientifique, Toulouse, France.
}

Copyright 2009 by the American Geophysical Union. 0094-8276/09/2009GL040396 $1^{\circ}$ [Inan et al., 1989], and can move electrons just above the loss cone edge into the loss cone. Subionospheric VLF measurements of LEP indicate large regions affected in individual bursts, with tens to hundreds of events observed from isolated storms [Peter and Inan, 2004]. Repeated interactions with lightning-generated whistler waves can result in scattering by multiple individual discharges within a storm or series of storms.

[4] The role of lightning in the formation of the slot region has long been in question. At relativistic energies $(>1 \mathrm{MeV})$, plasmaspheric hiss is thought to be the dominant loss mechanism [Lyons et al., 1972; Lyons and Thorne, 1973; Imhof et al., 1986]. Recently, Green et al. [2005] suggested lightning to be an embryonic source of hiss due to the geographic (preference over land masses) and local time (stronger in the afternoon sector) characteristics that are consistent with properties of lightning [Christian et al., 2003]. Observations of radiation belt losses due to LEP [Voss et al., 1998; Blake et al., 2001; Rodger and Clilverd, 2002] suggest that LEP may be an important loss mechanism at lower energies. Theoretical estimates have suggested that LEP might be a significant contributor to electron loss at mid-latitudes [Abel and Thorne, 1998], but experimental evidence of such a global role has been lacking. In this paper, we present a regionally averaged statistical assessment of electron fluxes in the drift loss cone and determine their relation to lightning. For this purpose the region of the continental United States is uniquely situated, due to the lack of land masses (and thus lightning activity) in the conjugate region and the fact that electrons scattered in this region accumulate in the drift loss cone until they precipitate at the SAA. The data from the DEMETER spacecraft (see below) is particularly valuable due to the large geometric factor of the electron detector and to the availability of data over a three-year period.

\section{Observations}

[5] DEMETER is in a $710 \mathrm{~km}$ altitude, polar and circular sun-synchronous orbit (10:30 LT and 22:30 LT) [Parrot et al., 2006]. We use data from the Instrument Champ Elecrique (ICE) which provides continuous measurements of the power spectrum of one electric field component in the VLF range $(15 \mathrm{~Hz}-17.4 \mathrm{kHz})$ [Berthelier et al., 2006]. We also use data from the Instrument for the Detection of Particles (IDP), measuring energetic electron fluxes in the energy range from $72.9 \mathrm{keV}$ to $2.35 \mathrm{MeV}$ with $4 \mathrm{~s}$ time resolution and $17.8 \mathrm{keV}$ energy resolution. The IDP has a large geometric factor of $1 \mathrm{~cm}^{2}$ sr, with a view angle of $\approx 30^{\circ}$ FWHM [Sauvaud et al., 2006]. The detector observes electrons with local pitch angles near $85^{\circ}$, which over the U.S. are in the drift loss cone (i.e., no trapped particles are 

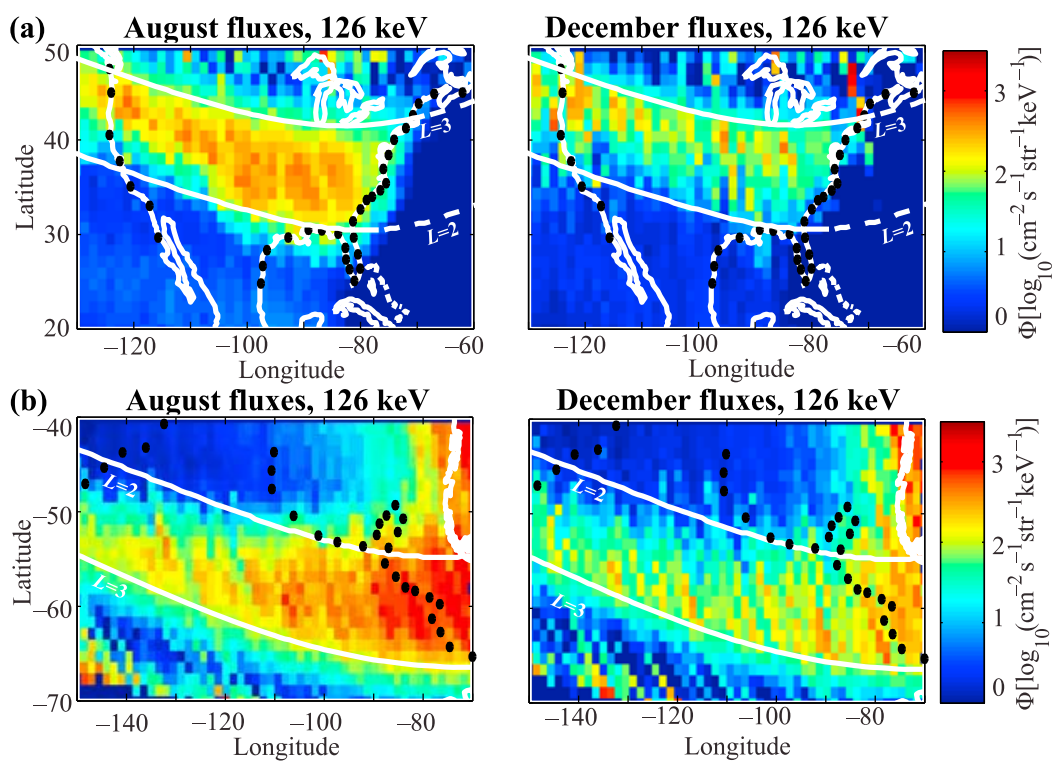

December fluxes, $126 \mathrm{keV}$
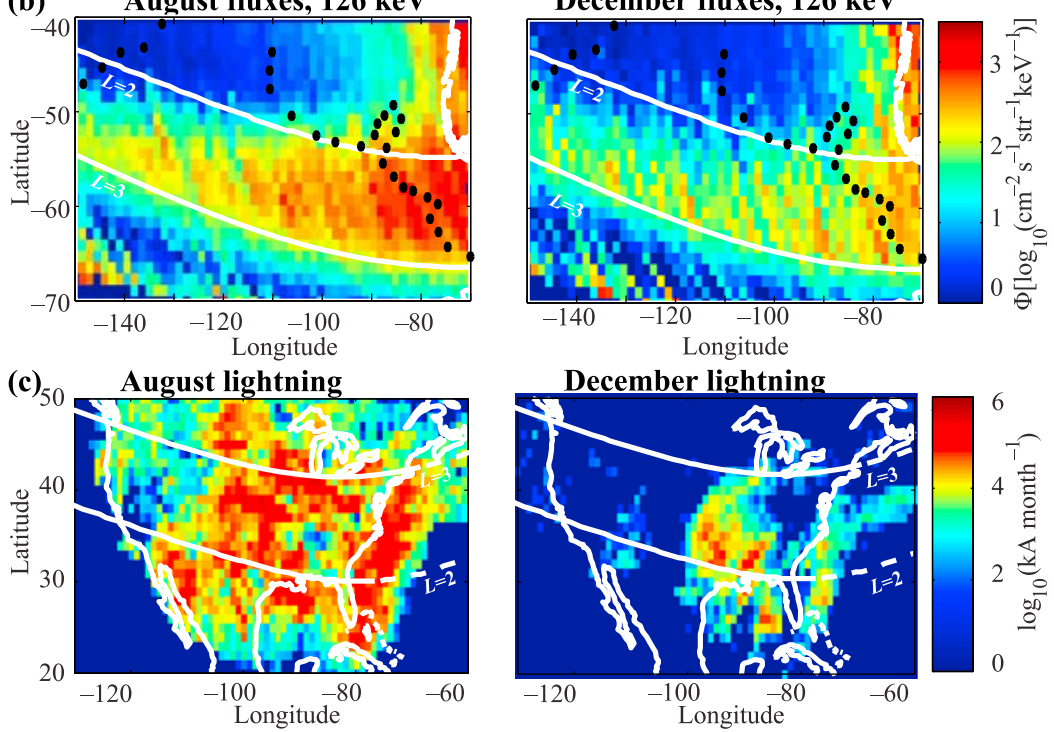

Figure 1. Seasonal variation of drift loss cone fluxes and lightning. (a) Median monthly $126 \mathrm{keV}$ fluxes in $1^{\circ}$ by $1^{\circ}$ latitude/longitude bins over the U.S. for August and December 2006-2008. L-shell contours at satellite altitude are shown for reference. (b) Median $126 \mathrm{keV}$ fluxes in conjugate region, denoted by black dots corresponding to U.S. coast. (c) Total lightning flash intensity in $1^{\circ}$ by $1^{\circ}$ latitude/longitude bins, for August and December 2006-2008.

detected in this longitude range), thus making these longitudes suitable for a particle precipitation study.

[6] Figure 1a shows the median monthly nighttime flux of $126 \mathrm{keV}$ electrons in bins of $1^{\circ}$ latitude by $1^{\circ}$ longitude, for August and December of 2006-2008. Only nighttime data are considered since trans-ionospheric absorption of VLF is significantly higher during the day [Helliwell, 1965, p. 71]. The energy of $126 \mathrm{keV}$ is within the observed range of $\approx 100-250 \mathrm{keV}$ for LEP events [Voss et al., 1984, 1998; Inan et al., 2007]; data for other energies in this range exhibit similar behavior (see Figure 4b). Figure 1b shows median nighttime fluxes in the geomagnetic conjugate region. Figure 1c shows the number of nighttime lightning strokes per month, weighted by peak current, in $1^{\circ}$ by $1^{\circ}$ latitude/longitude bins, as detected by the National Lightning Detection Network (NLDN) [Cummins et al., 1998] for the same months. Substantially higher lightning activity in August is accompanied by notably higher fluxes of drift loss cone electrons in both hemispheres, while lower lightning activity in December is accompanied by lower fluxes. The largest difference is in the central United States, where lightning activity is most intense and widespread. Termination of electron flux near the eastern boundary of the continental U.S. is due to the SAA which causes the mirroring points in the southern hemisphere to be below $150 \mathrm{~km}$. Even though lightning activity extends beyond the coast, DEMETER observes only transient fluxes in this region (marked by dashed lines on the $L$-shell traces in the top panels of Figure 1). Increased fluxes are, however, apparent in the geomagnetic conjugate region which is accessible to drift loss cone electrons.

[7] Full seasonal variation of both lightning and electron fluxes can be seen more clearly in Figure 2. Figure 2a shows median $126 \mathrm{keV}$ electron fluxes across five days (blue) and one month (red). These fluxes are median values spanning $2<L<3$ and $-100^{\circ}<$ longitude $<-80^{\circ}$. Figure $2 \mathrm{~b}$ shows lightning activity over the U.S. throughout the year in five-day and monthly averages. A broad peak in electron flux is clearly evident during the summer months of AprilSeptember, coincident with high lightning activity. August and December were chosen as representative months for summer and winter because they represented the most and least intense months of lightning activity. Each of the summer months shows a similar geographic distribution of electron flux and lightning to that shown in Figure 1. During the time (2006-8) of this study, average Kp values per month are below two, implying that increased fluxes in the slot region are being affected by lightning and are not the result of geomagnetic storms increasing the number of trapped particles available to be precipitated.

[8] Increased electron precipitation during summer months is also consistent with the seasonal distribution of VLF wave amplitudes observed on DEMETER. Figure 3 shows average nighttime $5-10 \mathrm{kHz}$ wave spectral-intensity 

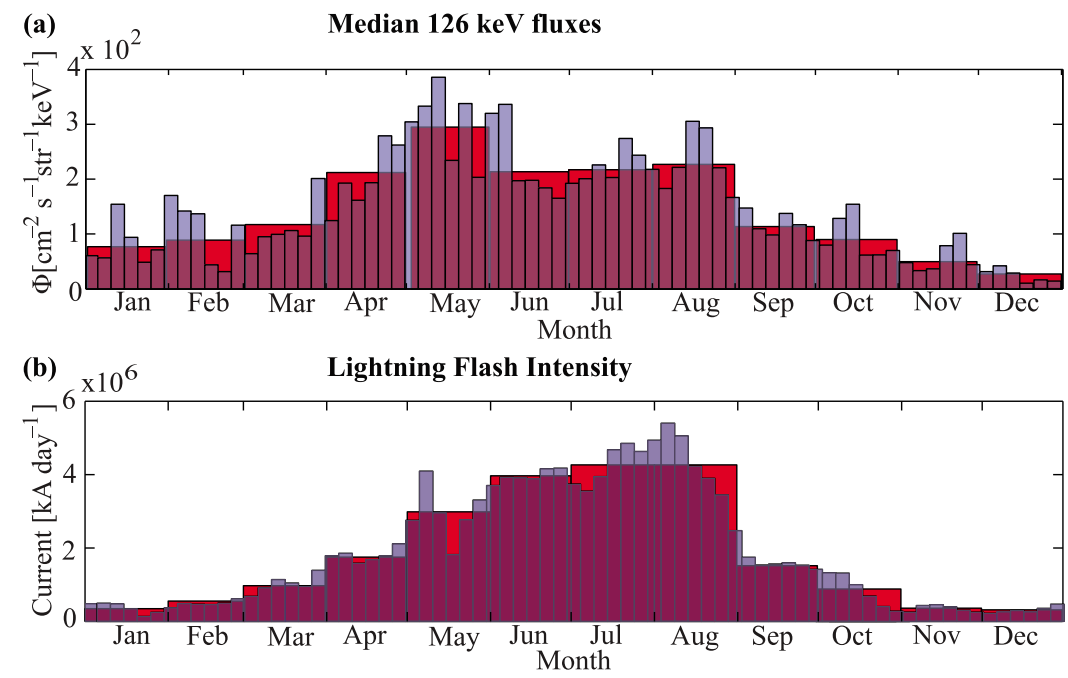

Figure 2. Yearly variation of fluxes and lightning. (a) Five-day (blue) and one month (red) median nighttime $126 \mathrm{keV}$ flux values over 2006-2008. (b) Average nighttime lightning flash intensity, shown in both five-day (blue) and one-month (red) sliding windows across 2006-2008.

in $1^{\circ}$ by $1^{\circ}$ latitude/longitude bins along the DEMETER ground track during August and December. As evidenced by these plots, wave spectral intensities over the U. S. dominate in the northern summer, whereas waves reaching $700 \mathrm{~km}$ are much less intense even in the south during southern summer (December). Waves observed in the southern hemisphere west of South America in August likely originate from U.S. lightning and propagate approximately along field lines to the southern hemisphere. This result is consistent with observations of highly-dispersed whistlers in this region with the DEMETER on-board neural network (M. Parrot et al., Penetration of lightning HF signals to the upper ionosphere over ground-based VLF transmitters, submitted to Journal of Geophysical Research, 2009) and with a lack of significant thunderstorm activity in this oceanic region [Christian et al., 2003]. The continental U.S. is the best region for a statistical study of seasonal variations of electron precipitation, not only because of its position with respect to the SAA (as mentioned above), but also because of the concentration of wave activity. The thin, laterally extended region of wave activity below Africa and Australia is due to a minimum in plasmaspheric electron density in this region during December solstice [Clilverd et $a l ., 2007]$, which brings the lower hybrid frequency (and the associated quasi-electrostatic wave activity, not of lightning origin) into the $5-10 \mathrm{kHz}$ range of the plot. The high wave intensities above Norway are produced by the EISCAT [Kimura et al., 1994] radar experiments.

\section{Discussion}

[9] Figure 4a shows equatorial cyclotron-resonant electron energy as a function of $L$-shell at six frequencies. A diffuse equilibrium model for cold plasma density was used with a population of $1000 \mathrm{el} \mathrm{cm}^{-3}$ on the equator at $L=3$ [Carpenter and Anderson, 1992] and a plasmapause location at $L=4$. Lightning discharges produce intense radiation at a few $\mathrm{kHz}$ to many $\mathrm{MHz}$ (typical peak at $5-10 \mathrm{kHz}$ [Rakov and Uman, 2003, p. 6], highlighted in red). Within the slot region $(2<L<3)$, lower energy electrons $(\approx 100-$ $350 \mathrm{keV})$ can resonate with the full frequency spectrum of the whistler wave, whereas at $L>3$, cyclotron-resonance with electrons $>100 \mathrm{keV}$ is unlikely. Figure $4 \mathrm{~b}$ shows the ratio of August and December median nighttime flux values in 2006-2008 as a function of energy at $L=2.4$ over the central and eastern U.S. $\left(-100^{\circ}\right.$ to $-80^{\circ}$ longitude). The largest seasonal differences occur between $100-350 \mathrm{keV}$, as predicted by the theoretical model in Figure 4a. Figure 4c shows the monthly median flux at $126 \mathrm{keV}$ as a function of $L$-shell in August and December over the same longitude region, and across the same three year period. It is evident that August fluxes in the slot region are significantly higher than those of December, demonstrating that a

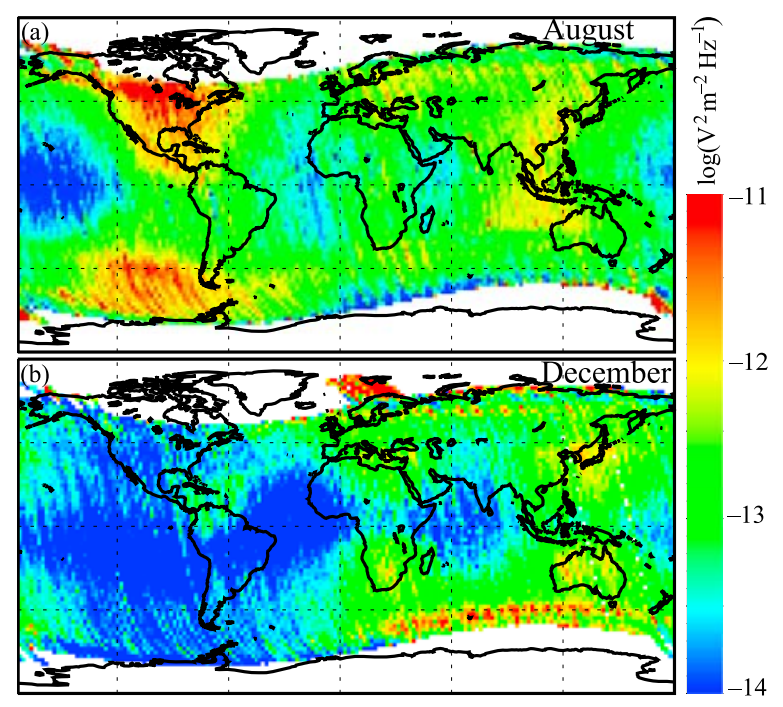

Figure 3. $5-10 \mathrm{kHz}$ wave spectral intensity on DEMETER. Global maps of the two year (2006-2007) monthly averages of nighttime wave spectral intensity $\left(\mathrm{V}^{2} \mathrm{~m}^{-2} \mathrm{~Hz}^{-1}\right)$ in the $5-10 \mathrm{kHz}$ range in (a) August and (b) December. 


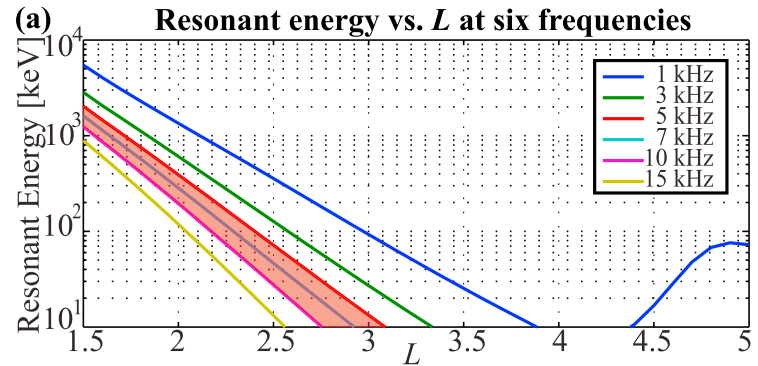

(b) Ratio of August and December median fluxes

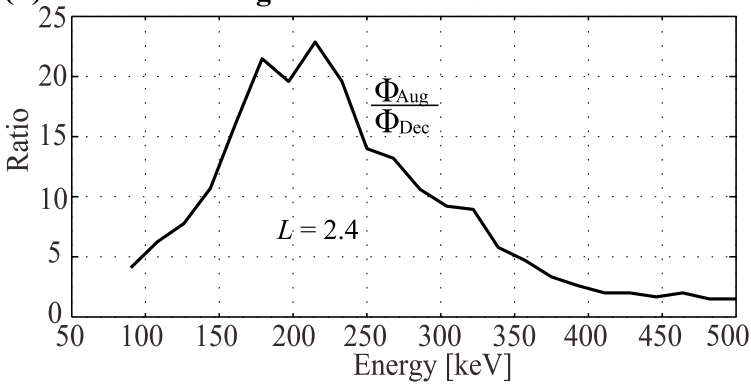

(c)

$126 \mathrm{keV}$ median flux vs. $L$

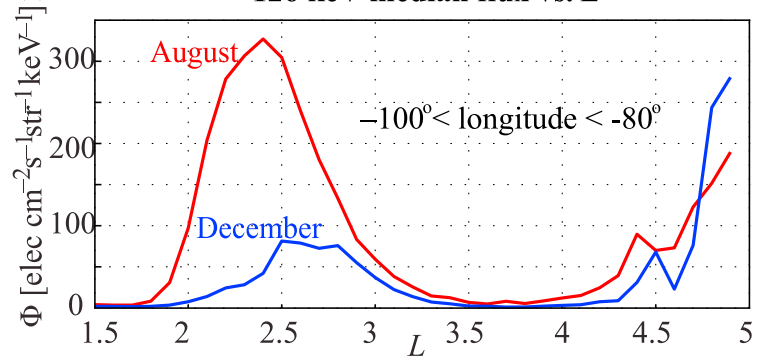

Figure 4. Electron flux variations with LEP. (a) Cyclotronresonant electron energy as a function of $L$-shell and frequency. (b) Ratio of median nighttime flux values in August and December over 2006-2008. (c) Median $126 \mathrm{keV}$ nighttime flux as a function of $L$-shell in August and December.

seasonal variation manifests in the slot region, whereas in the outer belt $(L>4)$, the seasonal differences are negligible.

[10] Based on the characteristics of median flux with both energy and $L$-shell, we conclude that most of the drift loss cone electron flux in the slot region is maintained by cyclotron-resonant interactions with whistler waves originating in lightning discharges. To confirm this relationship, we formulate daily numbers for drift loss cone fluxes at $126 \mathrm{keV}$ consisting of the summation of fluxes over nighttime passes in a region bounded by $L$-shells of 2 and 3 , and longitudes of $-100^{\circ}$ to $-80^{\circ}$, divided by the number of passes each day in this region. The daily lightning numbers are equal to the number of flashes per day, weighted by the magnitude of peak current of each flash, within two hours of 22:30 LT, the approximate local time of DEMETER passes. Using these two sets of values in 20062008, we find the Spearman rank correlation coefficient, $\rho$ to be 0.42 with a $p$-value of $10^{-3}$, implying significant correlation between lightning and loss cone electron fluxes. Although this correlation is significant, the coefficient indicates that U.S. lightning is not responsible for all precipitation in the slot region. Scattering takes place elsewhere and from other causes (i.e. hiss, chorus, etc.), but the role of lightning is important.

\section{Conclusions}

[11] Drift loss cone electron fluxes over the U.S. and its conjugate region show a broad maximum during the northern summer months. In addition, DEMETER VLF wave data exhibit a strong concentration over the U. S., peaking in the summer months, as would be expected given their lightning source. This seasonal variation suggests a prominent role of LEP in the loss of trapped radiation in the $2<L<$ 3 region. The data presented herein represent the first extension of heretofore transient and localized observations of LEP to a regionally averaged assessment of the role of lightning, suggesting that lightning plays an important role in affecting the lifetime of radiation belt electrons in the slot region.

[12] Acknowledgments. The Stanford portion of this work was supported by the Office of Naval Research under a Multi-University Research Initiative (MURI) program through subcontract 2882802-A to Stanford University from University of Maryland. The work of MP and JAS was supported by the Centre National d'Etudes Spatiales (CNES). The authors thank J. J. Berthelier, the PI of the electric field experiment onboard DEMETER, for the use of the data.

\section{References}

Abel, B., and R. M. Thorne (1998), Electron scattering loss in Earth's inner magnetosphere: 1. Dominant physical processes, J. Geophys. Res., 103, 2385-2396, doi:10.1029/97JA02919.

Berthelier, J. J., et al. (2006), ICE, the electric field experiment on DEMETER, Planet. Space Sci., 54, 456-471, doi:10.1016/j.pss. 2005.10.016.

Blake, J. B., U. S. Inan, M. Walt, T. F. Bell, J. Bortnik, D. L. Chenette, and H. J. Christian (2001), Lightning-induced energetic electron flux enhancements in the drift loss cone, J. Geophys. Res., 106, 29,73329,744, doi:10.1029/2001JA000067.

Carpenter, D. L., and R. R. Anderson (1992), An ISEE/Whistler model of equatorial electron density in the magnetosphere, J. Geophys. Res., 97, 1097-1108, doi:10.1029/91JA01548.

Christian, H. J., et al. (2003), Global frequency and distribution of lightning as observed from space by the Optical Transient Detector, J. Geophys. Res., 108(D1), 4005, doi:10.1029/2002JD002347.

Clilverd, M. A., N. P. Meredith, R. B. Horne, S. A. Glauert, R. R. Anderson, N. R. Thomson, F. W. Menk, and B. R. Sandel (2007), Longitudinal and seasonal variations in plasmaspheric electron density: Implications for electron precipitation, J. Geophys. Res., 112, A11210, doi:10.1029/ 2007JA012416.

Cummins, K. L., E. P. Krider, and M. D. Malone (1998), The U.S. National Lightning Detection Network and applications of cloud-to-ground lightning data by electric power utilities, IEEE Trans. Electromagn. Compat., 40, 465-480, doi:10.1109/15.736207.

Green, J. L., S. Boardsen, L. Garcia, W. W. L. Taylor, S. F. Fung, and B. W. Reinisch (2005), On the origin of whistler mode radiation in the plasmasphere, J. Geophys. Res., 110, A03201, doi:10.1029/2004JA010495.

Helliwell, R. A. (1965), Whistlers and Related Ionospheric Phenomena, Stanford Univ. Press, Stanford, Calif.

Imhof, W. L., H. D. Voss, M. Walt, E. E. Gaines, J. Mobilia, D. W. Datlowe, and J. B. Reagan (1986), Slot region electron precipitation by lightning, VLF chorus, and plasmaspheric hiss, J. Geophys. Res., 91, 8883-8894, doi:10.1029/JA091iA08p08883.

Inan, U. S., D. C. Shafer, W. Y. Yip, and R. E. Orville (1988), Subionospheric VLF signatures of nighttime $\mathrm{D}$ region perturbations in the vicinity of lightning discharges, J. Geophys. Res., 93, 11,455-11,472.

Inan, U. S., M. Walt, H. Voss, and W. Imhof (1989), Energy spectra and pitch angle distribution of lightning-induced electron precipitation: Analysis of an event observed on the S81-1 (SEEP) satellite, J. Geophys. Res., 94, 1379-1401.

Inan, U. S., D. Piddyachiy, W. B. Peter, J. A. Sauvaud, and M. Parrot (2007), DEMETER satellite observations of lightning-induced electron precipitation, Geophys. Res. Lett., 34, L07103, doi:10.1029/2006GL029238.

Kimura, I., P. Stubbe, M. T. Rietveld, R. Barr, K. Ishida, Y. Kasahara, S. Yagitani, and I. Nagano (1994), Collaborative experiments by 
Akebono satellite, Troms ionospheric heater, and European incoherent scatter radar, Radio Sci., 29, 23-37.

Lyons, L. R., and R. M. Thorne (1973), Equilibrium structure of radiation belt electrons, J. Geophys. Res., 78, 2142-2149, doi:10.1029/ JA078i013p02142.

Lyons, L. R., R. M. Thorne, and C. F. Kennel (1972), Pitch-angle diffusion of radiation belt electrons within the plasmasphere, J. Geophys. Res., 77, 3455-3474, doi:10.1029/JA077i019p03455.

Parrot, M., et al. (2006), The magnetic field experiment IMSC and its data processing onboard DEMETER: Scientific objectives, description and first results, Planet. Space Sci., 54, 441-455, doi:10.1016/ j.pss.2005.10.015.

Peter, W. B., and U. S. Inan (2004), On the occurrence and spatial extent of electron precipitation induced by oblique nonducted whistler waves, J. Geophys. Res., 109, A12215, doi:10.1029/2004JA010412.

Rakov, V. A., and M. A. Uman (2003), Lightning: Physics and Effects, Cambridge Univ. Press, New York.

Rodger, C. J., and M. A. Clilverd (2002), Inner radiation belt electron lifetimes due to whistler-induced electron precipitation (WEP) driven losses, Geophys. Res. Lett., 29(19), 1924, doi:10.1029/2002GL015795.

Sauvaud, J. A., T. Moreau, R. Maggiolo, J.-P. Treilhou, C. Jacquey, A. Cros, J. Coutelier, J. Rouzaud, E. Penou, and M. Gangloff (2006),
High-energy electron detection onboard DEMETER: The IDP spectrometer, description and first results on the inner belt, Planet. Space Sci., 54, 502-511, doi:10.1016/j.pss.2005.10.019.

Voss, H. D., W. L. Imhof, M. Walt, J. Mobilia, E. E. Gaines, J. B. Reagan, U. S. Inan, R. A. Helliwell, D. L. Carpenter, and J. P. Katsufrakis (1984), Lightning-induced electron precipitation, Nature, 312, 740-742.

Voss, H. D., M. Walt, W. L. Imhof, J. Mobilia, and U. S. Inan (1998), Satellite observations of lightning-induced electron precipitation, J. Geophys. Res., 103, 11,725-11,744.

E. S. Gemelos and M. Walt, STAR Laboratory, Stanford University, Packard Bldg., 350 Serra Mall, Stanford, CA 94305, USA. (egemelos@ stanford.edu)

U. S. Inan, Electrical Engineering Department, KOC University, Rumelifeneri Yolu, 34450 Sariyer, Istanbul, Turkey.

M. Parrot, Laboratoire de Physique et Chimie de l'Environnement et de l'Espace, CNRS, 3A avenue de la Recherche Scientifique, F-45071 Orléans CEDEX 2, France.

J. A. Sauvaud, Centre d'Etude Spatiale des Rayonnements, CNRS, 9 avenue du Colonel Roche, BP 4346, F-31028 Toulouse CEDEX 4, France. 